\title{
Towards inhibitors of glycosyltransferases: A novel approach to the synthesis of 3-acetamido- 3-deoxy-D-psicofuranose derivatives
}

\author{
Maroš Bella ${ }^{*}$, Miroslav Koóš ${ }^{1}$ and Chun-Hung Lin ${ }^{2}$
}

\author{
Full Research Paper \\ Address: \\ ${ }^{1}$ Institute of Chemistry, Slovak Academy of Sciences, Dúbravská \\ cesta 9, SK-845 38, Bratislava, Slovakia and ${ }^{2}$ Institute of Biological \\ Chemistry, Academia Sinica, No. 128 Academia Road Sec. 2, Taipei \\ 11529, Taiwan \\ Email: \\ Maroš Bella* - chemmajo@savba.sk \\ * Corresponding author \\ Keywords: \\ glycosyltransferases; inhibitors; D-psicofuranose; synthesis; \\ thioglycosylation
}

Open Access

\author{
Beilstein J. Org. Chem. 2015, 11, 1547-1552. \\ doi:10.3762/bjoc. 11.170
}

Received: 30 June 2015

Accepted: 20 August 2015

Published: 04 September 2015

\begin{abstract}
Dedicated to the memory of Professor Harry S. Mosher (1915-2001), a great chemist, a fantastic teacher and colleague, and a wonderful person in recognition of his contributions to the organic chemistry.
\end{abstract}

Associate Editor: S. Flitsch

(C) 2015 Bella et al; licensee Beilstein-Institut. License and terms: see end of document.

\begin{abstract}
A novel synthetic strategy leading to 3-acetamido-3-deoxy-D-psicofuranose 9 is presented. The latter compound, after some manipulations, was transformed into fully protected 3-acetamido-3-deoxy-D-psicofuranose $\mathbf{1 1}$ as a potential substrate for the synthesis of $\mathrm{N}$-acetylglucosaminyltransferase inhibitors designed by computational methods. After the attempted thioglycosylation of 11 with EtSH in the presence of $\mathrm{BF}_{3} \cdot \mathrm{OEt}_{2}, 2$-methyloxazoline derivatives $\mathbf{1 3}$ and $\mathbf{1 4}$ were isolated.
\end{abstract}

\section{Introduction}

Glycosyltransferases (GTs) belong to a family of enzymes that are responsible for the biosynthesis of complex oligosaccharides, glycoproteins and other glycoconjugates in mammalian biological systems. These glycoconjugates are operating in the cell and on the cell surface, particularly as glycoproteins, and are involved in many vital biological processes, such as cell-cell communication, signal transduction, activation and response of the immune system etc. [1,2]. On the other hand, an uncontrolled glycosylation caused by genetic mutations of GTs leads to structural changes in various glycoconjugates which contribute to many mammalian diseases $[3,4]$. In addition, the role played by the glycoconjugates changes markedly during disease development such as malignant transformation [5], cancer cell proliferation and metastases spreading [6]. Since glycosyltransferases (GTs) are entailed in the biosynthesis of glycans and glycoconjugates, which are involved in these disease processes, inhibitors of GTs are of great therapeutic potential and attract remarkable interest for drug development.

Although the mechanism of reactions catalyzed by glycosyltransferases has been investigated thoroughly, many aspects of the catalytic mechanism remain unknown [7]. In general, GTs transfer sugar nucleotide donors onto suitable acceptors during 
the biosynthesis of glycans and glycoconjugates [8]. Both donor and acceptor substrates are recognized by GTs binding pockets. For instance, in the course of biosynthesis of complex and hybrid oligosaccharides, the insertion of an $\mathrm{N}$-acetylglucosaminyl moiety (GlcNAc-) into an oligosaccharide chain was identified as the crucial step catalyzed by $N$-acetylglucosaminyltransferases (GnTs) in the presence of a metal co-factor. In this catalytic reaction, UDP-GlcNAc [uridine 5'-(2-acetamido-2-deoxy-D-glucopyranosyl diphosphate)] acts as the donor of the GlcNAc residue while a hydroxy group situated at a specific site of the growing oligosaccharide chain serves as the acceptor [9].

The target-directed search for effective GnTs inhibitors based on the rational design of model compounds remains a difficult task due to the complexity of the GnTs catalytic mechanism. The main reasons originating from the complex character of the catalytic mechanism which complicate the search for GnTs inhibitors are a) participation of four components in the transition state (sugar donor, acceptor, nucleotide and metal co-factor), b) weak binding of the enzymes to natural substrates, and c) lack of structural data [10]. Various methods have been applied in order to unveil effective GTs inhibitors [11-16]. The most important approaches are based on the design of acceptor analogues, donor analogues and transition state mimetics. Despite all the effort and the numerous GTs inhibitors identified, only a few achieved significant activity. On the basis of the previous investigations, a new class of GTs inhibitors imitating carbohydrates has been revealed [17]. These structurally modified carbohydrates are designed to simulate the shape and functionality of the natural substrates in the ground and/or the transition state (TS) of the enzymatic reaction [14]. In the case of GTs inhibitors, the carbohydrate mimetics that imitate the TS of the enzymatic reactions should exhibit a higher inhibition activity than the natural carbohydrate substrates $[9,16]$. Investigations of the catalytic mechanism of inverting glycosyltransferases [18] and $\mathrm{N}$-acetylglucosaminyltransferase I [19] by employing ab initio calculations resulted in the design of inhibitors based on carbohydrate mimetics that simulate the transition state of the enzymatic reaction (Figure 1).

Within the structure of the proposed inhibitors of $\mathrm{N}$-acetylglucosaminyltransferases (Figure 1), the ethyl, benzyl and/or phenyl groups imitate the acceptor substrate and the "1-thio" linker provides the proper distance between the "donor" and the "acceptor" together with the charge distribution as it was calculated for the TS $[9,10]$.

In this contribution, attention is focused on the synthesis of the saccharide moiety of potential GnTs inhibitors (framed struc-

\section{saccharide part of proposed}

GnTs inhibitors

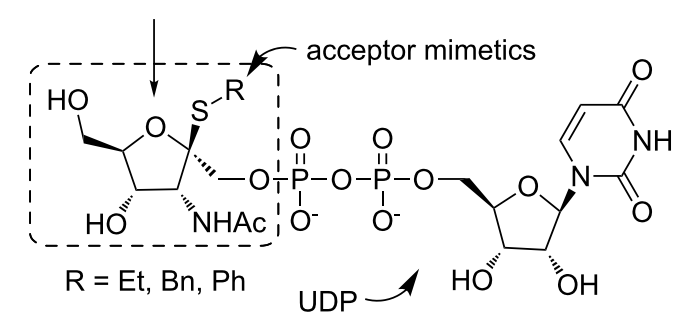

Figure 1: Proposed structure of GnTs inhibitors.

ture in Figure 1). In this respect, a novel approach to 3-acetamido-3-deoxy-D-psicofuranose derivatives, based on the transformation of D-mannose, is described. In addition, the thioglycosylation of fully protected 3-acetamido-3-deoxy-Dpsicofuranose 11 with ethanethiol was examined under various conditions.

\section{Results and Discussion}

The synthesis of the saccharide moiety of potential GnTs inhibitors started from commercially available D-mannose. The latter was transformed into suitably protected 1,2:4,5-di-O-isopropylidene-6-O-pivaloyl-D-mannitol (1) in three steps by the procedures described in the literature [20-22]. The standard preparation of mesylate with methanesulfonyl chloride and $\mathrm{Et}_{3} \mathrm{~N}$ as base smoothly provided 1,2:4,5-di- $O$-isopropylidene-3-Omethanesulfonyl-6-O-pivaloyl-D-mannitol (2) in 93\% yield (Scheme 1).

In the next step, the treatment of mesylate 2 with sodium azide in refluxing aqueous DMF afforded 3-azido-3-deoxy-1,2:4,5-di$O$-isopropylidene-6-O-pivaloyl-D-altritol (3) in a low yield $(23 \%)$. The addition of a catalytic amount of tetrabutylammonium chloride ( 0.15 equiv) to the reaction mixture in order to form tetrabutylammonium azide in situ did not improve the yields of the substitution. In the course of the nucleophilic substitution, unidentified elimination products were observed as the prevailing constituents of the reaction mixture together with the desired 3-azido derivative 3 . The majority of the byproducts were separated by column chromatography on silica gel (EtOAc/hexane 1:10). A complete separation of the elimination products from 3 was not necessary since they were readily removed in the next step. An analytically pure sample of $\mathbf{3}$ was obtained by additional column chromatography. In order to increase the yield of azide 3 by replacing 3-O-mesylate 2 with the corresponding 3-O-triflate in the nucleophilic substitution reaction with sodium azide, the $O$-protected mannitol derivative 1 was treated with triflic anhydride in the presence of pyridine. However, the resulting 3-O-triflate was unstable and decomposed rapidly after the work-up. On the other hand, an 


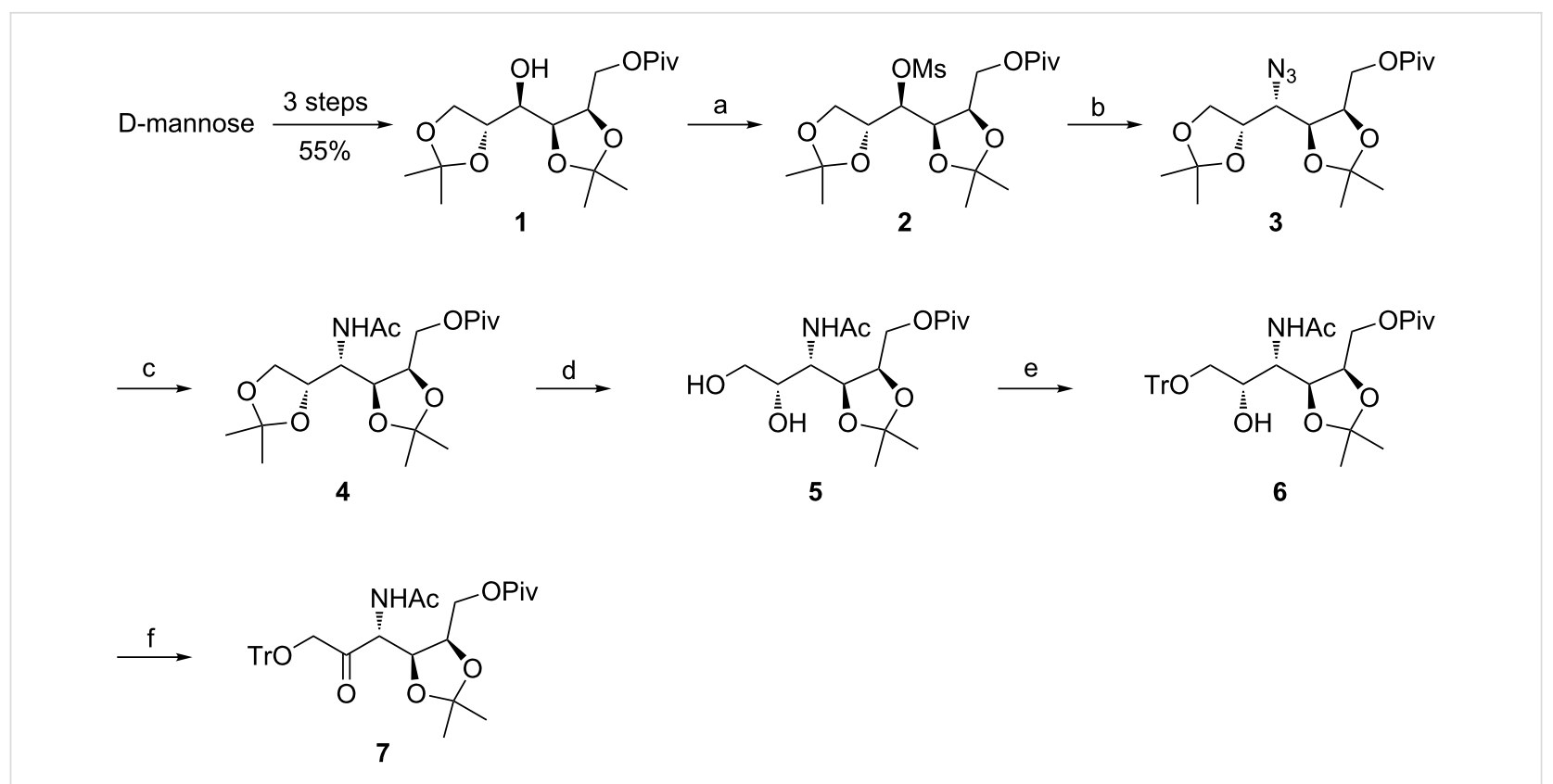

Scheme 1: Reagents and conditions: a) $\mathrm{MsCl}, \mathrm{Et}_{3} \mathrm{~N}, \mathrm{CH}_{2} \mathrm{Cl}_{2}, 0{ }^{\circ} \mathrm{C} \rightarrow \mathrm{rt}$, overnight, $93 \%$; b) $\mathrm{NaN}_{3}, \mathrm{H}_{2} \mathrm{O} / \mathrm{DMF}$ 1:20 (v/v), reflux, $9 \mathrm{~h}, 23 \%$; c) i: $\mathrm{Zn} / \mathrm{NH}_{4} \mathrm{Cl}, \mathrm{H}_{2} \mathrm{O} / \mathrm{EtOH} 1: 3(\mathrm{v} / \mathrm{v})$, rt, $2 \mathrm{~h}$, ii: AcCl, pyridine, $\mathrm{CH}_{2} \mathrm{Cl}_{2}, \mathrm{rt}, 30 \mathrm{~min}, 80 \%$ (2 steps); d) $70 \% \mathrm{AcOH}, \mathrm{rt}$, overnight, $71 \%$; e) TrCl, Et $3 \mathrm{~N}$, $\mathrm{CH}_{2} \mathrm{Cl}_{2}, 0{ }^{\circ} \mathrm{C} \rightarrow \mathrm{rt}$, overnight, $88 \%$; f) DMP, $\mathrm{CH}_{2} \mathrm{Cl}_{2}$, rt, overnight, $95 \%$.

attempted tosylation of alcohol 1 using $\mathrm{TsCl}$ and pyridine in $\mathrm{CH}_{2} \mathrm{Cl}_{2}$ did not proceed, probably due to steric hindrance, and only the starting material was recovered. Next, the azide $\mathbf{3}$ (contaminated with some elimination products) was subjected to reduction with powdered $\mathrm{Zn}$ and $\mathrm{NH}_{4} \mathrm{Cl}$ as reducing agents [23] followed by acetylation to afford 3-acetamido-3-deoxy1,2:4,5-di- $O$-isopropylidene-6- $O$-pivaloyl-D-altritol (4) in a good yield. It should be mentioned that the reduction of compound 3 under the Staudinger protocol $\left(\mathrm{PPh}_{3}, \mathrm{H}_{2} \mathrm{O} / \mathrm{THF}\right)$ was found to be slow and ineffective. The following selective acidic hydrolysis of 1,2-O-isopropylidene ketal in 4 using 70\% $\mathrm{AcOH}$ led to 3-acetamido-3-deoxy-4,5-O-isopropylidene-6- $O$ pivaloyl-D-altritol (5). Subsequently, the selective protection of the primary hydroxy group in diol $\mathbf{5}$ as trityl ether under standard conditions followed by the oxidation of the free secondary hydroxy group in 3-acetamido-3-deoxy-4,5-O-isopropylidene6-O-pivaloyl-1-O-trityl-D-altritol (6) with Dess-Martin periodinane yielded a protected open-chain form of 3-acetamido-3deoxy-D-psicose, namely 3-acetamido-3-deoxy-4,5-Oisopropylidene-6- $O$-pivaloyl-1- $O$-trityl-D-psicose (7) in an excellent yield (Scheme 1). This compound represents the key intermediate for the further synthesis of 3-acetamido-3-deoxyD-psicofuranose derivatives bearing variously protected or unprotected hydroxy groups on the furanose ring. For example, the treatment of 7 with concentrated $\mathrm{H}_{2} \mathrm{SO}_{4}$ in methanol resulted in a mixture of anomeric methyl 3-acetamido-3-deoxy6- $O$-pivaloyl- $\alpha / \beta$-D-psicofuranosides (8) in $71 \%$ yield (Scheme 2).
Based on the integration of the ${ }^{1} \mathrm{H}$ NMR signals of the acetamide group in derivatives 8 , a 3:2 ratio of the anomers was determined, albeit without the exact assignment of anomeric configurations to particular anomers. In the context of the synthesis of the saccharide part of GnTs inhibitors, psicose derivative 7 was subjected to a simultaneous hydrolysis of the trityl ether and the 4,5-O-isopropylidene ketal with concentrated $\mathrm{H}_{2} \mathrm{SO}_{4}$ in $70 \% \mathrm{AcOH}$ to afford 3-acetamido-3-deoxy-6-O-

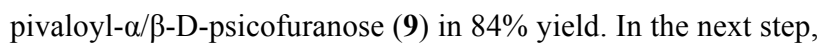
the hydroxy groups of 9 in positions 1 and 2 were protected as isopropylidene ketal. Although both anomers were formed together with 3-acetamido-3-deoxy-4,5-O-isopropylidene-6- $O$ pivaloyl-D-psicose as a byproduct originating from isopropylidenation of the open-chain form of 9 , only the $\alpha$-anomer, namely 3-acetamido-3-deoxy-1,2-O-isopropylidene-6- $O$ pivaloyl- $\alpha$-D-psicofuranose (10), was isolated in $63 \%$ yield. The $\beta$-anomer was detected in a negligible amount and could not be separated from the above-mentioned byproduct. Acetylation of the 4-hydroxy group in derivative $\mathbf{1 0}$ under standard conditions yielded fully protected 3 -acetamido-4-O-acetyl-3deoxy-1,2- $O$-isopropylidene-6- $O$-pivaloyl- $\alpha$-D-psicofuranose (11) as the suitable substrate for thioglycosylation. Attempts to determine the configuration at the anomeric center in compounds 10 or 11 by employing NOE NMR technique were ambiguous. Although both derivatives 10 and 11 were crystalline solids, it was not possible to obtain suitable crystals for single-crystal X-ray analysis. However, removal of the pivaloyl group from derivative $\mathbf{1 0}$ afforded 3-acetamido-3-deoxy-1,2-O- 


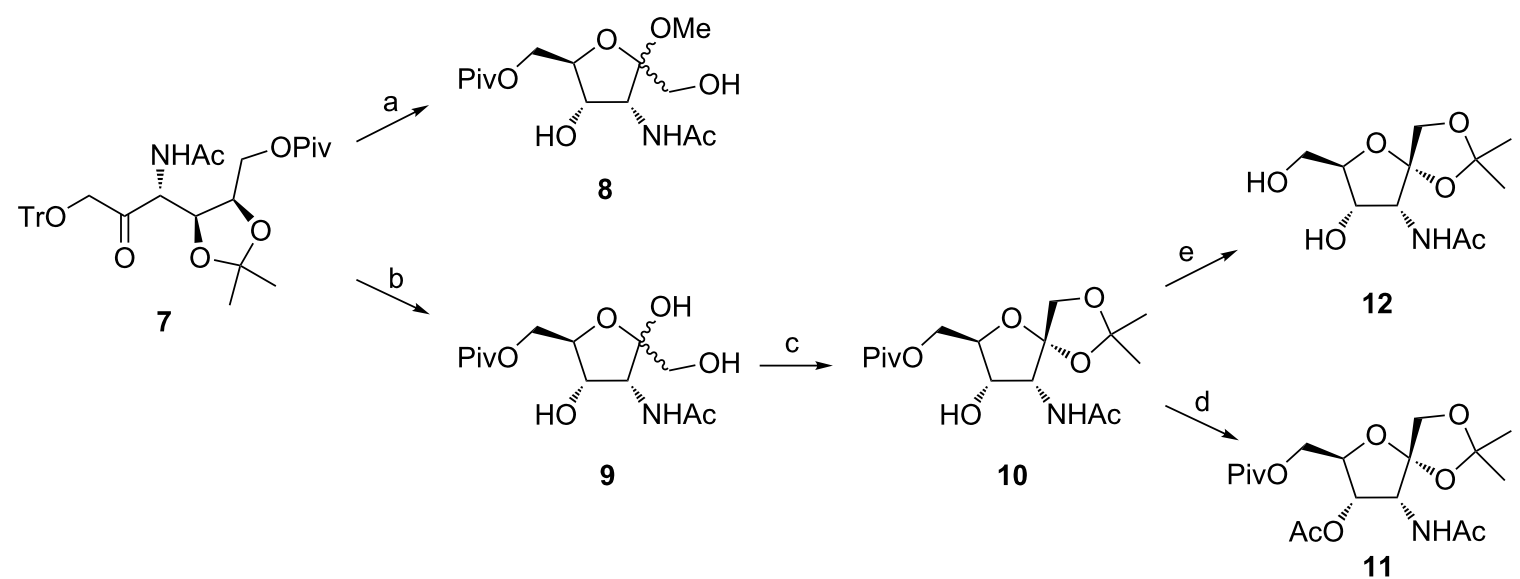

Scheme 2: Reagents and conditions: a) $\mathrm{H}_{2} \mathrm{SO}_{4}, \mathrm{MeOH}$, rt, overnight, $71 \%$; b) $\mathrm{H}_{2} \mathrm{SO}_{4}, 70 \% \mathrm{AcOH}, 0{ }^{\circ} \mathrm{C} \rightarrow \mathrm{rt}, 4 \mathrm{~h}, 84 \%$; c) 2,2 -dimethoxypropane, acetone, PTSA, rt, $4 \mathrm{~h}, 63 \%$; d) $\mathrm{Ac}_{2} \mathrm{O}$, pyridine, $\mathrm{CH}_{2} \mathrm{Cl}_{2}$, rt, overnight, $92 \%$; e) $\mathrm{MeONa}, \mathrm{MeOH}$, rt, overnight, $97 \%$.

isopropylidene- $\alpha$-D-psicofuranose (12) which, after crystallization (EtOAc/hexane 1:2), afforded crystals suitable for X-ray analysis. This unambiguously confirmed the $\alpha$-configuration at C-2 of furanose 12 (Figure 2). Consequently, based on this information, the $\alpha$-configurations at the anomeric center of derivative $\mathbf{1 0}$ as well as $\mathbf{1 1}$ were determined.

The crucial step leading to the target saccharide part of potential GnTs inhibitors represents the thioglycosylation of the fully protected psicofuranose derivative $\mathbf{1 1}$ with ethanethiol as the model thiolating agent. However, the treatment of $\mathbf{1 1}$ with EtSH and $\mathrm{BF}_{3} \cdot \mathrm{OEt}_{2}$ led predominantly to 2-methyloxazoline derivatives 13 and 14, while the required ethyl 3-acetamido-3-deoxy6-O-pivaloyl-2-thio- $\beta$-D-psicofuranoside (15) was detected only in traces as a mixture with the corresponding $\alpha$-anomer 16 (Scheme 3).

Further attempts to achieve the thioglycosylation of D-psicofuranose derivative 11 under various conditions, including EtSH/ TMSOTf $/ \mathrm{CH}_{2} \mathrm{Cl}_{2}$, EtSH/TMSOTf and EtSH/CSA/ $\mathrm{CH}_{2} \mathrm{Cl}_{2}$ did not improve the yield of the required 2 -thio- $\beta$-D-psicofuranoside derivative 15.

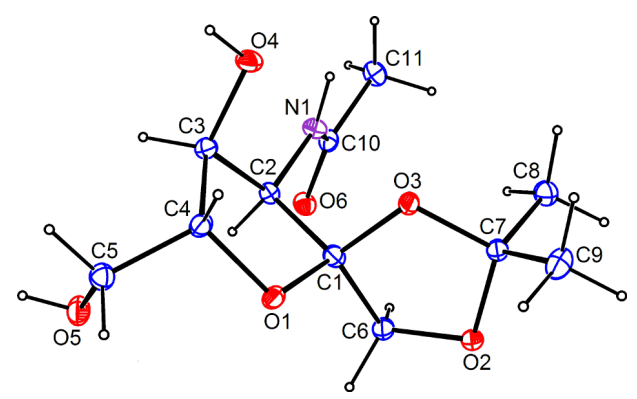<smiles>CC(=O)NC1[C@H](O)[C@@H](CO)O[C@]12COC(C)(C)O2</smiles>

Figure 2: Molecular structure (ORTEP drawing with adjacent ChemDraw image) of compound 12. Atomic displacement ellipsoids are drawn at $30 \%$ probability level.<smiles>CCC1(C)OC[C@@]2(OC(CONc3ccccc3)C(OC(C)=O)C2NC(C)=O)O1</smiles>

11<smiles>CC(=O)OCC1OC2(CO)OC(C)=N[C@H]1C2ONc1ccccc1</smiles>

13<smiles>CCSC[C@@]12CC(CO[PH+])C(O[R4](C)=O)C1N=C(C)O2</smiles>

14<smiles>CCS[C@]1(CO)OC(CO[PbH])C(OC(C)=O)[C@H]1NC(C)=O</smiles>

15<smiles>CCS[C@]1(CO)OC(CO[Pb])[C@@H](NC(C)=O)[C@H]1NC(C)=O</smiles>

16 


\section{X-ray analysis}

Single crystals (stable at ambient temperature) that were suitable for X-ray diffraction measurements were obtained by slow crystallization of $\mathbf{1 2}$ from EtOAc/hexane 1:2 with cooling in a refrigerator. The preliminary orientation matrices and final cell parameters were obtained using the Siemens SMART and Siemens SAINT software [24]. The data were empirically corrected for absorption and other effects using the SADABS program [25]. The crystal and experimental data for compound

Table 1: Crystallographic and experimental data ${ }^{a}$ for compound 12.

Crystal data

\begin{tabular}{ll}
\hline Empirical formula & $\mathrm{C}_{11} \mathrm{H}_{19} \mathrm{NO}_{6}$ \\
Formula weight/mass & 261.27 \\
Crystal size & $0.420 \times 0.060 \times 0.040 \mathrm{~mm}$ \\
Crystal description & needle \\
Crystal colour & colourless \\
Crystal system & monoclinic \\
Space group & $C 2$ \\
Unit cell dimensions & $a=18.8306(8) \AA$ \\
& $b=5.4573(2) \AA$ \\
Volume & $c=13.1363(6) \AA$ \\
$Z$ & $1234.02(9) \AA^{3}$ \\
Calculated density & 4 \\
Absorption coefficient & $1.406 \mathrm{Mg}^{3} \mathrm{~m}^{3}$ \\
F(000) & $0.114 \mathrm{~mm}^{-1}$ \\
\end{tabular}

Data collection

Measurement device type

Measurement method

Bruker APEX-II CCD

Temperature

$\omega$-scans

100(2) K

Wavelength

$0.71073 \AA$

Monochromator

$\theta$ range for data collection

Index ranges

Graphite

1.696 to $27.102^{\circ}$

$-24<=h<=24,-6<=k<=$

$6,-16<=$ l $<=16$

$24125 / 2712[R($ int $)=0.0592]$

Reflections collected/unique

Completeness to $\theta=25.000^{\circ}$

Absorption correction

$100.0 \%$

Semi-empirical from

equivalents

Max. and min. transmission

0.9705 and 0.9123

Refinement

Refinement method

Data/restraints/parameters

Goodness-of-fit on $F^{2}$

Final $R$ indices $[1>2 \sigma(\mathrm{I})]$

$R$ indices (all data)

Largest diff. peak and hole

Full-matrix least-squares on

$F^{2}$

$2712 / 3 / 179$

1.065

$R_{1}=0.0338, w R_{2}=0.0664$

$R_{1}=0.0418, w R_{2}=0.0698$

0.163 and -0.176 e. $\AA^{-3}$

aStandard deviations are given in parentheses.

12 are summarized in Table 1. The structure was resolved by direct methods and refined by full-matrix least-squares on all $F^{2}$ data using SHELXS-97 [26] and SHELXL2013 [27]. The non$\mathrm{H}$ atoms were refined anisotropically.

Based on the calculated values of the ring-puckering parameters [28] $Q=0.376(2) \AA$ and $\Phi=50.6(4)^{\circ}$ and relevant torsion angles (Table 2), the five-membered $\mathrm{O} 1-\mathrm{C} 1-\mathrm{C} 2-\mathrm{C} 3-\mathrm{C} 4$ furanose ring (O5-C2-C3-C4-C5 according to the IUPAC hexofuranose nomenclature [29]) in $\mathbf{1 2}$ adopts the ${ }^{2} T_{1}$ conformation ( ${ }^{\mathrm{C} 2} T_{\mathrm{C} 1}$, twisted on $\left.\mathrm{C} 1-\mathrm{C} 2, \mathrm{C} 1-e x o, \mathrm{C} 2-e n d o\right)$. For the fivemembered 1,3-dioxolane ring (O2-C6-C1-O3-C7), the puckering parameters $Q=0.288(2) \AA$ and $\Phi=15.7(5)^{\circ}$ and relevant torsion angles (Table 2) are indicative of ${ }^{\mathrm{O}} T_{1}$ conformation ( ${ }^{\mathrm{O} 2} T_{\mathrm{C} 6}$, twisted on $\left.\mathrm{O} 2-\mathrm{C} 6, \mathrm{C} 6-e x o, \mathrm{O} 2-e n d o\right)$. The absolute configuration at chiral atoms $\mathrm{C} 2, \mathrm{C} 3$, and $\mathrm{C} 4$ of the $\mathrm{O} 1-\mathrm{C} 1-\mathrm{C} 2-\mathrm{C} 3-\mathrm{C} 4$ furanose ring (Figure 2) was assigned on the basis of the known arrangement in analogous D-psicofuranose derivatives. The $\alpha$-D-configuration at the anomeric atom $\mathrm{C} 1$ was established on the basis of inspection of the relevant torsion angles (Table 2).

\begin{tabular}{|c|c|c|}
\hline Ring & Torsion angle & Value \\
\hline \multirow[t]{5}{*}{ Furanose } & $\mathrm{O} 1-\mathrm{C} 1-\mathrm{C} 2-\mathrm{C} 3$ & $39.5(2)$ \\
\hline & $\mathrm{C} 1-\mathrm{C} 2-\mathrm{C} 3-\mathrm{C} 4$ & $-28.8(2)$ \\
\hline & $\mathrm{C} 2-\mathrm{C} 3-\mathrm{C} 4-\mathrm{O} 1$ & $9.0(2)$ \\
\hline & C3-C4-O1-C1 & $16.6(2)$ \\
\hline & C4-O1-C1-C2 & $-34.9(2)$ \\
\hline \multirow[t]{5}{*}{ 1,3-Dioxolane } & $\mathrm{O} 2-\mathrm{C} 6-\mathrm{C} 1-\mathrm{O} 3$ & $24.0(2)$ \\
\hline & $\mathrm{C} 6-\mathrm{C} 1-\mathrm{O} 3-\mathrm{C} 7$ & $-7.9(2)$ \\
\hline & $\mathrm{C} 1-\mathrm{O} 3-\mathrm{C} 7-\mathrm{O} 2$ & $-11.2(2)$ \\
\hline & $\mathrm{O} 3-\mathrm{C} 7-\mathrm{O} 2-\mathrm{C} 6$ & $26.9(2)$ \\
\hline & $\mathrm{C} 7-\mathrm{O} 2-\mathrm{C} 6-\mathrm{C} 1$ & $-31.6(2)$ \\
\hline \multirow[t]{6}{*}{ Anomeric center } & $\mathrm{C} 3-\mathrm{C} 2-\mathrm{C} 1-\mathrm{O} 3$ & $-78.7(2)$ \\
\hline & $\mathrm{C} 3-\mathrm{C} 2-\mathrm{C} 1-\mathrm{C} 6$ & $162.24(18)$ \\
\hline & C4-O1-C1-O3 & $83.7(2)$ \\
\hline & C4-O1-C1-C6 & $-161.35(19)$ \\
\hline & $\mathrm{N} 1-\mathrm{C} 2-\mathrm{C} 1-\mathrm{O} 3$ & $44.1(2)$ \\
\hline & $\mathrm{N} 1-\mathrm{C} 2-\mathrm{C} 1-\mathrm{C} 6$ & $-75.0(2)$ \\
\hline
\end{tabular}

aStandard deviations are given in parentheses.

\section{Conclusion}

In summary, a new synthetic strategy leading to the formation of a 3-acetamido-3-deoxy-D-psicofuranose frame is presented. The attempted thioglycosylation of fully protected 3 -acetamido3 -deoxy- $\alpha$-D-psicofuranose 11 resulted in ring closure of the acetamido group, affording 2-methyloxazoline derivatives $\mathbf{1 3}$ 
and 14. Further research into an alternative strategy for the synthesis of 3-azido-3-deoxy-D-psicofuranose derivatives will be performed so as to avoid the formation of the 2-methyloxazoline ring.

\section{Supporting Information}

\section{Supporting Information File 1}

Experimental procedures and spectral data.

[http://www.beilstein-journals.org/bjoc/content/

supplementary/1860-5397-11-170-S1.pdf]

\section{Acknowledgements}

The financial support received from the Slovak Research and Development Agency (Grant no. APVV-0484-12), Scientific Grant Agency (Grant nos. VEGA 2/0064/15 and 1/0962/12) and the SAS-Taiwan project (Grant no. SAS-NSC 2012/8) is gratefully acknowledged. This contribution is the result of the project implementation: Centre of Excellence for Glycomics, ITMS26240120031, supported by the Research \& Development Operational Programme funded by the ERDF. The technical assistance afforded by Ms Beáta Kalivodová is gratefully acknowledged.

\section{References}

1. Varki, A.; Cummings, R. D.; Esko, J. D.; Freeze, H. H.; Stanley, P. Essentials of Glycobiology, 2nd ed.; Cold Spring Harbor Laboratory Press: New York, 2009.

2. Weis, W. I.; Taylor, M. E.; Drickamer, K. Immunol. Rev. 1998, 163, 19-34. doi:10.1111/j.1600-065X.1998.tb01185.x

3. Glycoproteins and disease. In New comprehensive biochemistry; Montreuil, J.; Vliegenthart, J. F. G.; Schachter, H., Eds.; Elsevier: Amsterdam, The Netherlands, 1996; Vol. 30.

4. Marquardt, T.; Freeze, H. Biol. Chem. 2001, 382, 161-177. doi:10.1515/BC.2001.024

5. Hakomori, S. Proc. Natl. Acad. Sci. U. S. A. 2002, 99, 10231-10233. doi:10.1073/pnas.172380699

6. Dennis, J. W.; Laferté, S.; Waghorne, C.; Breitman, M. L.; Kerbel, R. S. Science 1987, 236, 582-585. doi:10.1126/science.2953071

7. Ünligil, U. M.; Rini, J. M. Curr. Opin. Struct. Biol. 2000, 10, 510-517. doi:10.1016/s0959-440x(00)00124-x

8. Breton, C.; Fournel-Gigleux, S.; Palcic, M. M. Curr. Opin. Struct. Biol. 2012, 22, 540-549. doi:10.1016/j.sbi.2012.06.007

9. Hirsch, J.; Koóš, M.; Tvaroška, I. Chem. Pap. 2009, 63, 329-335 doi:10.2478/s11696-009-0008-8

10. Raab, M.; Kozmon, S.; Tvaroška, I. Carbohydr. Res. 2005, 340, 1051-1057. doi:10.1016/j.carres.2005.01.041

11. Look, G. C.; Fotsch, C. H.; Wong, C.-H. Acc. Chem. Res. 1993, 26, 182-190. doi:10.1021/ar00028a008

12. Sears, P.; Wong, C.-H. Proc. Natl. Acad. Sci. U. S. A. 1996, 93, 12086-12093. doi:10.1073/pnas.93.22.12086

13. Wang, R.; Steensma, D. H.; Takaoka, Y.; Yun, J. W.; Kajimoto, T.; Wong, C.-H. Bioorg. Med. Chem. 1997, 5, 661-672. doi:10.1016/S0968-0896(97)00005-9
14. Sears, P.; Wong, C.-H. Angew. Chem., Int. Ed. 1999, 38, 2300-2324. doi:10.1002/(SICI)1521-3773(19990816)38:16<2300::AID-ANIE2300> 3.0.CO;2-6

15. Elhalabi, J. M.; Rice, K. G. Curr. Med. Chem. 1999, 6, 93-116.

16. Waldscheck, B.; Streiff, M.; Notz, W.; Kinzy, W.; Schmidt, R. R. Angew. Chem., Int. Ed. 2001, 40, 4007-4011. doi:10.1002/1521-3773(20011105)40:21<4007::AID-ANIE4007>3.0. $\mathrm{CO} ; 2-\mathrm{F}$

17. Compain, P.; Martin, O. R. Bioorg. Med. Chem. 2001, 9, 3077-3092. doi:10.1016/S0968-0896(01)00176-6

18. Tvaroška, I.; André, I.; Carver, J. P. J. Am. Chem. Soc. 2000, 122, 8762-8776. doi:10.1021/ja001525u

19. Tvaroška, I.; André, I.; Carver, J. P. Glycobiology 2003, 13, 559-566. doi:10.1093/glycob/cwg067

20. Schmidt, O. T. Methods Carbohydr. Chem. 1963, 2, 318-324.

21. Shen, X.; Wu, Y.-L.; Wu, Y. Helv. Chim. Acta 2000, 83, 943-953. doi:10.1002/(SICI)1522-2675(20000510)83:5<943::AID-HLCA943>3.0. $\mathrm{CO} ; 2-\mathrm{H}$

22. Frick, W.; Krülle, T.; Schmidt, R. R. Liebigs Ann. Chem. 1991, 435-438. doi:10.1002/jlac.199119910179

23. Lin, W.; Zhang, X.; He, Z.; Jin, Y.; Gong, L.; Mi, A. Synth. Commun. 2002, 32, 3279-3284. doi:10.1081/scc-120014032

24. SMART \& SAINT; Bruker AXS Inc.: Madison, WI, USA, 2003.

25. SADABS, Version 2.10; University of Göttingen: Germany, 2003.

26. Sheldrick, G. M. Acta Crystallogr., Sect. A 2008, 64, 112-122. doi:10.1107/s0108767307043930

27. Gruene, T.; Hahn, H. W.; Luebben, A. V.; Meilleur, F.; Sheldrick, G. M. J. Appl. Crystallogr. 2013, 47, 462-466. doi:10.1107/s1600576713027659

28. Cremer, D.; Pople, J. A. J. Am. Chem. Soc. 1975, 97, 1354-1358. doi:10.1021/ja00839a011

29. McNaught, A. D. Pure Appl. Chem. 1996, 68, 1919-2008. doi:10.1351/pac199668101919

\section{License and Terms}

This is an Open Access article under the terms of the Creative Commons Attribution License (http://creativecommons.org/licenses/by/2.0), which permits unrestricted use, distribution, and reproduction in any medium, provided the original work is properly cited.

The license is subject to the Beilstein Journal of Organic Chemistry terms and conditions:

(http://www.beilstein-journals.org/bjoc)

The definitive version of this article is the electronic one which can be found at: doi:10.3762/bjoc. 11.170 